\title{
Canales de riego: creación de un paisaje agrícola en el valle del Mayo, Sonora, 1863-1904\%
}

\section{Gustavo LorenZana DuráN}

Es profesor del Departamento de Historia y Antropología de la Universidad de Sonora (México). Correo electrónico: glorenzana@sociales.uson.mx. El autor es Doctor en Historia y Estudios Regionales de la Universidad Veracruzana (México). Entre sus capítulos de libros recientes tenemos: en coatoría con María del Carmen Bojórquez, "Acequias, molinos y presas: conflictos por el recurso del agua en el distrito de Hermosillo, 1825-1840", en La Palabra, lenguaje, medios y sociedades digitales, eds. Manuel Arana Nava e Irma Perea-Henze (Chihuahua: Universidad Autónoma de Chihuahua-Universidad de Sonora-Instituto Nacional de Historia y Antropología de Chihuahua, 2014), 355-370 y "Litigios por el uso agrícola del agua en el distrito político-administrativo de Hermosillo, Sonora, 1879-1899”, en Escasez y gestión del agua en el Norte de México, eds. Cecilis Sheridan y Hernán Salas (México D.F.: CIESAS-Instituto de Investigaciones Antropológicas (UNAM), 2013). Su línea de investigación son los estudios sobre la historia de los usos sociales del agua en Sonora en los años 1754-1953.

Recibido: 25 de julio de 2014

Aprobado: 14 de septiembre de 2014

Modificado: 12 de octubre de 2014

Artículo de investigación e innovación

DOI: http://dx.doi.org/10.15648/hc.26.2015.3

* $\quad$ Este artículo forma parte del proyecto "Tenencia de la tierra e historia ambiental en los pueblos del río Sonora y pueblos de la Sierra (Antigua Opatería), siglos XIX y XX”, financiado por la Dirección de Ciencias Sociales del Departamento de Historia y Antropología de la Universidad de Sonora (México).

Esta publicación está bajo una licencia Creative Commons Reconocimiento-Compartir Igual 3.0

\section{(cc) BY-SA}


Canales de riego: creación de un paisaje agrícola en el valle del Mayo, Sonora, 1863-1904

\title{
Resumen
}

Los objetivos del artículo son por una parte, presentar las percepciones que sobre el clima y la construcción social del potencial de la llanura semidesértica, elaboraron actores sociales a través del tiempo. Por la otra, analizar el proceso de apertura de canales de riego, como la expresión de la alteración de la naturaleza y la construcción de un paisaje agrícola.

Palabras clave: Infraestructura hidráulica, naturaleza, paisaje agrícola, actores sociales.

Irrigation channels: the creation of an agicultural landscape at the Mayo river, Sonora, 1863-1904

\begin{abstract}
The goals of this article are, by one side, to show the perceptions about the climate and the social building of capacity in the semi desertic plain, elaborated by the social actors through time. On the other side, to analize the irrigation channels constructive process, as an expression of environment alteration and the creation of an agricultural landscape.
\end{abstract}

Key words: Hydraulic infrastructure, environment, agricultural landscape, social actors.

Canais de irrigação: a criação de uma paisagem agrícola no rio Mayo, Sonora, 1863-1904

\section{Resumo}

Os objetivos deste artigo são, por um lado, mostrar as percepções sobre o clima e a construção social da capacidade na planície semi desértica, elaboradas pelos atores sociais através do tempo. Por outro lado, analisar o processo construtivo dos canais de irrigação, como uma expressão das alterações ao ambiente e a criação de uma paisagem agrícola.

Palavras-chave: Infra-estrutura hidráulica, ambiente, paisagem agrícola, atores sociais. 
Les canaux d'irrigation: la création d'un paysage agricole à la rivière Mayo, Sonora, 1863-1904

\section{Résumé}

Les objectifs de cet article sont, d'un côté, montrer les perceptions sur le climat et la construction sociale de la capacité dans la plaine demi désertique, élaboré par les acteurs sociaux à travers le temps. De l'autre côté, analize les processus de construction de canaux d'irrigation, comme une expression de l'altération environnement et la création d'un paysage agricole.

Mots-clés: L’infrastructure hydraulique, environnement, paysage agricole, les acteurs sociaux.

\section{INTRODUCCIÓN}

El asunto de la construcción de paisajes por parte de los seres humanos a partir de actividades económicas, no es algo que podamos encontrar en la historiografía que sobre el devenir histórico sonorense se ha generado en los últimos años, con excepción de los trabajos de la historiadora estadounidense Cynthia Radding, para los casos de la llamada Pimería Alta y la Opatería. No está por demás decir, que hacemos nuestro el planteamiento de la citada investigadora en torno a los paisajes, "entendido como espacios de vida, creados por la actividad humana; los paisajes surgen de procesos ecológicos y culturales dotados de poder para transformar los desiertos, sabanas, bosques y ríos con la intervención del hombre y de la naturaleza"1.

Asimismo, compartimos lo expresado por Antonio Escobar Ohmstede, de tomar "en cuenta los cambios en el paisaje, vistos como procesos históricos que se desenvuelven en espacios culturales creados y observados por el hombre. Los paisajes, a través de los cuales percibimos la naturaleza,

1 Cynthia Radding, Paisajes de poder e identidad: fronteras imperiales en el desierto de Sonora y bosque de la Amazonia (México: CIESAS-UAM-Azcapotzaclo-El Colegio de Sonora, 2005), 24. 
son en sí hechura humana"2. Esta es la ruta que seguiremos para historiar la alteración de la naturaleza de una parte de la llanura semidesértica y la construcción social de un paisaje agrícola. El periodo bajo estudio está marcado por el inicio, 1863 y término, 1904, de la apertura de canales en la parte baja de la cuenca del río Mayo.

\section{El escenario}

El valle del Mayo, se ubica en el estado de Sonora en la posición de $27^{\circ}$ 04' 51" latitud norte y $109^{\circ} 26^{\prime} 43^{\prime}$ ' longitud oeste. Forma parte de la provincia fisiográfica conocida con el nombre de Sierras Sepultadas. Comprende más del $50 \%$ de la extensión del estado de Sonora y se divide en tres subprovincias: Desierto de Sonora, Llanura Costera y Estribaciones de Piemonte. Tiene una extensión de $104491 \mathrm{Km}^{2}$ y abarca la parte occidental de los estados de Sonora, Sinaloa y Nayarit. Limita al norte con el valle de Yuma, Arizona, al oriente con la Sierra Madre Occidental, al sur y al poniente, con el Mar de Cortés y el Océano Pacífico ${ }^{3}$.

La llanura costera en la entidad sonorense tiene varios cientos de kilómetros, y comprende desde la parte sur del municipio de Guaymas hasta el municipio de Huatabampo. Dicha extensión comprende $9.245 .44 \mathrm{~km}^{2}$. En ella se ubican los deltas de los ríos Yaqui y Mayo. El territorio está cubierto por material aluvial. El clima que prevalece en esta región, entendida como una delimitación geográfica, es seco cálido con lluvias en verano ${ }^{4}$. La temperatura en el verano supera los $40^{\circ}$ centígrados. En el invierno, desciende a $19^{\circ}$ centígrados.

\section{Percepciones sobre el Clima y el ambiente}

En el año de 1835, Ignacio Zúñiga, comisionado por el gobierno federal para realizar el registro de los recursos naturales existentes en la entidad

2 Antonio Escobar Ohmstede, "Cambios en el paisaje hidroagrario ¿La Revolución un detonante? El caso de San Luis Potosí (1910-1940)”, en Relaciones. Estudios de historia y sociedad, Vol. XXXIV,

3 Luis Velázquez Aguirre y Anselmo Ordaz Ayala, "Provincias hidrogeológicas de México", en Boletinsgm.igeolcuunam.mx/bsgm/vols/época 03/5201/velazquez-aguirre.pdf

4 Sonora.sitecproduce.org.mx/Estado/fisiografía\#fisiografía, página consultada 20 de abril de 2013. 
sonorense, dejó apuntado que el clima entre Álamos y Tucson, era "naturalmente dulce y sano" 5 . Por su parte, José Agustín de Escudero, más de una década después, dio cuenta que el clima de Sonora y Sinaloa, "a pesar de ser caliente, es por lo general saludable y acomodado"

Otro factor que le es inherente a la entidad sonorense son sus escasas lluvias en verano e invierno. La precipitación media anual en el estado de Sonora es de $405 \mathrm{~mm}$. En el valle del Mayo alcanza los $555 \mathrm{~mm}^{7}$. Este fenómeno meteorológico fue registrado por el bachiller José Joaquín de Zayas, cura del pueblo de la Natividad de Navojoa, en agosto de 1772, al apuntar que los habitantes, incluidos los mayos del mencionado pueblo y los de San Ignacio, Cohuirimpo, habían perdido sus siembras debido a la exigüidad de las lluvias ${ }^{8}$. La agricultura de temporal practicada por los mayos dependía de que se presentaran lluvias abundantes tanto en verano como en invierno. La mención de las siembras por parte de Zayas, es importante, porque da cuenta de creación de un paisaje agrícola por algunos mayos, en una parte de la llanura semidesértica.

Los paisajes agrícolas creados por los hombres también tuvieron lugar en las tierras altas de Sonora, conocida como la Cordillera. Cynthia Radding nos dice que "los paisajes agrícolas se combinaban con estrechas llanuras aluviales, pequeñas parcelas de hortalizas regadas manualmente y plantaciones en laderas que dependían de precipitaciones de temporada" . Debido a lo anterior, compartimos la idea expresada por la mencionada historiadora respecto a que "el ambiente no es un mero telón de fondo escénico del drama humano, sino que forma parte del relato humano"10.

Tanto en el valle del Mayo como en la Cordillera, a los pueblos indios se Ignacio Zúñiga, Rápida ojeada al Estado de Sonora (1835) (Hermosillo: Gobierno del Estado de Sonora, 1985), 57.

6 José Agustín de Escudero, Noticias Estadísticas de Sonora y Sinaloa (Hermosillo: Universidad de Sonora. 1997), 98.

7 www.ceasonora.gob.mx/archivos/admin/ 22-25, página consultada el 20 de abril de 2013.

8 Archivo General de la Nación (AGN). Ramo: Provincias Internas, Vol. 17.

$9 \quad$ Cynthia Radding, Paisajes, 52.

10 Cynthia Radding, 17. Para esta historiadora "naturaleza el ambiente físico, con sus restricciones topográficas, climáticas, hidrográficas y biológicas, así como los paisajes creados por el hombre y los significados culturales que conllevan", 16-17. 
les sumaron otros actores sociales: los misioneros jesuitas, militares, representantes de estructura de gobierno y colonos, quienes también, construyeron paisajes a través de la congregación de las rancherías dispersas en pueblos cabecera y pueblos de visita, en el caso de los ignacianos. Los militares por medio de la edificación de presidios en puntos estratégicos. Los colonos tuvieron como estímulo la presencia de los recursos tierra y agua. Para el acceso a la primera, actuaron en consecuencia con lo establecido en la Real Instrucción de 1754.

Por medio de esta norma, se convocó a los poseedores de tierras realengas a entrar en composición con la Hacienda real. A los demás, se les invitó a denunciar dichos terrenos. Cabe decir, a unos y a otros, se les exigía contar con un buen número de semovientes de ganado vacuno, caballar y mularr ${ }^{11}$. Sin duda, la presencia de los hatos en una parte de la ya mencionada llanura semidesértica, es otra muestra de la alteración de la naturaleza por la actividad ganadera y por ende, la construcción de un paisaje pecuario.

Tenemos por tanto, que en el valle del Mayo y las tierras altas de Sonora, la ganadería y la agricultura, eran actividades que algunos actores sociales llevaban a cabo. Respecto a la segunda actividad, Nicolás de Lafora, observó que los indios en las márgenes de los ríos tenían siembras cuyo ciclo estaba en relación con el uso y aprovechamiento de las avenidas de las corrientes superficiales $^{12}$. El subdelegado del Real de Los Álamos, Tomás Pelayo, en los primeros años del siglo XIX, destacó la disminución de las cosechas de maíz, trigo, garbanzo y frijol debido a la escasez de las lluvias, durante la temporada de cultivo ${ }^{13}$.

Ya en la década de los años 60 del mencionado siglo, F. A. Ronstadt, prefecto del distrito de Álamos, reconoció que debido a la exigüidad de las lluvias únicamente la recibía "una pequeña parte de los fértiles terrenos"14.

11 Gustavo Lorenzana Durán, “Tierra, agua y mercado en el distrito de Álamos, Sonora, 1754-1915”, (tesis de Doctorado, Instituto de Investigaciones Histórico-Sociales de la Universidad Veracruzana, 2002), 96, 109.

12 Nicolás Lafora, Relación del viaje que hizo a los presidios internos situados en la frontera de la América septentrional perteneciente al rey de España (México: Editorial Pedro Robredo, 1939), 154.

13 Archivo Franciscano-Biblioteca Nacional de México (AF-BNM) caja 36, exp., 36/819.4, ff. 17-20.

14 Pesqueira, Documentos para la historia de Sonora, 1863-1864, primera parte, Tomo I. Mecanoescrito ubicado en la Sala del Noroeste de la Biblioteca Fernando Pesqueira de la Universidad de Sonora. 
La práctica de agricultura de secano en las márgenes del río Mayo y en las otras corrientes superficiales de Sonora, la regularidad y abundancia de las lluvias, a diferencia de la vegetación arbustiva: cactáceas arbóreas como el cardón pelón o gigante; el cardón espinoso, la pitahaya y el sahuaro, que alcanzan gran tamaño. Tienen una antigüedad de más de 80 millones de años ${ }^{15}$.

Otras especies son el mezquite, la cholla, palo verde y gobernadora. Se caracterizan por su adaptación a la aridez. Todas forman parte del matorral xerófilo. Una especie que llamó la atención del misionero jesuita Juan Nentuig, fue la pitahaya, debido a la fruta que daba desde mayo hasta julio. El ignaciano registró el proceso de creación de la fruta:

"a principios o mediados de mayo unas flores blancas o algo moradas, las cuales se van secando a cosa de 15 días, y creciendo el botón que está pegado sin pezón al vástago, el cual queda verde, hasta que ya llegado el tamaño de un huevo de gallina coge color y se pone encarnado, señal de que ya está madura esta fruta, que se da en la mayor parte con tanta abundancia, que los indios hacen cosecha para venderla o guardarla"16.

Nentuig, con la última parte de su registro, destacó la actividad recolectora de frutos de la naturaleza que los indios llevaban a cabo, quizás más con el segundo propósito que el primero. Tal actividad en el momento del registro del ignaciano no generó ninguna tensión entre los actores sociales. ¿Por qué razón? Los frailes estaban abocados a la explotación de las tierras de misión y al comercio de sus productos, y los españoles que llegaron al septentrión novohispano, observaron "una tierra muy seca, con escasas fuentes de agua, con cañadas de pastos buenos, pero también con muchos montes en donde ni el pasto nace y son intransitables" ${ }^{17}$. Tal condición hi-

15 Cecilia Leonor Jiménez Sierra, “Las cactáceas mexicanas y los riesgos que enfrentan”, Revista Digital Universitaria, Vol. 12, No. 1, (2011): 4.

16 Juan Nentuig, El Rudo ensayo. Descripción geográfica, natural y curiosa de la provincia de Sonora, 1764. (México: INAH, 1977), 57-58.

17 Archivo General del Estado de Sonora (AGES) Fondo: Títulos Primordiales, t. XVIII, exp., 236. 
drológica se compensa con los buenos pastos para el pastoreo del ganado de diferentes tipos.

Con la palabra montes, primero los españoles y después, los sinaloenses y sonorenses se refirieron a la abundante vegetación de matorral xerófilo en amplias extensiones de tierra. El registro de lo anterior lo encontramos en las diligencias de denuncios y composiciones de sitios de ganado mayor. En 1762, el juez subdelegado del distrito de Álamos, José Álvarez, al terminar las medidas del puesto llamado San Francisco de Bacamocha, apuntó lo siguiente: "tenía varios pedazos de consideración sin ningún uso por tantos montes"18.

Ya en las postrimerías del dominio español, el juez privativo de ventas y composiciones de tierras y aguas de la Intendencia de Arizpe, José Juan Lombán, describió las tierras ubicadas en la hoy llamada llanura costera del Pacífico como "yermas, con montes, cerros y llénales inmensos poblados de chollas"19. Este era el ambiente a modificar por parte de los actores sociales. Mientras tanto, en la década de los años 30 del siglo XIX, Luis Urrutia, no pudo medir el puesto Agiabampo por ser "un monte de espinos cerrados" $" 20$.

Lo agreste del ambiente de la citada llanura no minimizó el reconocimiento realizado por misioneros, funcionarios y militares, en torno al fluir de las aguas por las corrientes superficiales y la fertilidad de las vegas de las mismas. Uno de ellos fue el jesuita Andrés Pérez de Ribas, quien se refirió al río Mayo en los siguientes términos: "no era muy caudaloso ya que casi todo el año se podía pasar, menos en el tiempo de las crecientes que al recoger muchas aguas ensancha su madre, dejando regados y fertilizados algunos valles. Era el más poblado de gente de todos los de Sinaloa, siendo todos labradores" ${ }^{\prime 2}$. De nueva cuenta, la referencia al paisaje agrícola construido por los seres humanos.

18 AGES, Fondo: Títulos Primordiales, t. VI, exp., 61.

19 María del Carmen Bojórquez Jusaino, "Del Pitic a distrito de Hermosillo. La colonización del espacio, 1744-1852. Una descripción a través de la privatización de la tierra" (tesis de pregrado en Licenciatura, Universidad de Sonora, 2004).

20 AGES, Fondo: Títulos Primordiales, t. I, exp., 18.

21 Andrés Pérez de Ribas, Historia de los Triumphos de nuestra Santa Fe (México: Siglo XXI Editores-DIFOCUR, 1992), 237. 
Por su parte, el doctor Pedro Tamarón y Romeral, en su visita que hizo a la provincia de Sinaloa, destacó la descarga de las aguas de los ríos llamados Sinaloa, Fuerte y Mayo en el seno californio. El jerarca eclesiástico, destacó la presencia de cultivos de trigo, maíz y otras semillas en las márgenes de los arroyos. Al igual, que en el valle del Mayo, se aprovechaban las tierras irrigadas por las avenidas de las corrientes superficiales ${ }^{22}$. Antonio de los Reyes, primer obispo de Sonora, apuntó que tanto los mayos como las misiones de Camoa, Navojoa y Santa Cruz del Mayo, contaban con buenas tierras en las orillas del río Mayo, para la práctica de la agricultura ${ }^{23}$. Alejo García Conde, en su carácter de intendente de Arizpe, destacó que en "Sonora, las vegas de los ríos son fertilísimas y hay fuentes y arroyos que contribuyen a la feracidad del país" 24 .

El diputado occidental Carlos Espinosa de los Monteros, también puso el acento en la fertilidad de la provincia de Sinaloa: "Era bañada por quince caudalosos ríos y muchísimos arroyos, los cuales pareciera que habían sido colocados por la naturaleza para regar a poco gasto las inmensas llanuras de la costa, siendo tan fecunda la tierra que cuando se dispone para la siembra, los labradores prefieren estos terrenos a pesar de sus costos para prepararlos"25.

El secretario de gobierno del Estado de Occidente, Ignacio López, estuvo en sintonía con la idea anterior al decir, que el citado estado tenía "abundancia de terrenos fértiles ubicados en distintos climas y casi todos vírgenes conforme los crió el Autor Supremo"26. Los miembros del Ayuntamiento de Álamos, en el marco del debate de la separación de Sonora y Sinaloa, se inclinaron por su integración a la primera por la identificación con sus costumbres, pero sobre todo, porque "muy cerca se encontraban

22 Pedro Tamarón y Romeral, Demostración del vastísimo obispado de la Nueva Vizcaya, 1765. Durango, Sinaloa, Sonora, Arizona, Nuevo México, Chihuahua y porciones de Texas, Coahuila y Zacatecas. (México: Antigua Librería Robredo, 1937), 249.

23 AGN, Ramo: Misiones, Vol., 14, exp., 8

24 AF-BNM, caja 37/ exp., 37/838.1.

25 Exposición que sobre las provincia de Sonora y Sinaloa escribió el diputado Carlos Espinoza de los Monteros (México: Imprenta de Mariano Ontiveros, 1825), 4. Fue diputado ante el Congreso del Estado Interno de Occidente.

26 Armando Quijada Hernández, Sonora. Génesis de su soberanía (Hermosillo: Gobierno del Estado de Sonora, 1981), 4. 
los valles del Yaqui y Mayo, en cuyas tierras fértiles se podrían alcanzar grandes producciones que algún día llamarían la atención del mundo"27.

Zúñiga, adjudicó el carácter vivaz, alegre y activo de los yaquis y mayos a "la clara y hermosa atmósfera que respiran, el cielo siempre diáfano, y el risueño aspecto de sus campiñas y de los ríos que las riegan"28. De lo dicho hasta aquí, hay dos asuntos a destacar. El primero es la idea de que los terrenos fértiles son espacios vacíos, por ende sitios a ocupar por parte de otros actores sociales que no son los pueblos indios ni los indios. El segundo, tiene que ver con la construcción social del potencial de la llanura semidesértica a partir del binomio tierra y agua.

La idea de una naturaleza pródiga hacia los occidentales contrasta con la postura de Georges Louis Leclerc, conde de Buffon: "la naturaleza salvaje es horrible y letal, soy yo y únicamente yo quien puede convertirla en grata y habitable" 29 . ¿Cómo alcanzar tales atributos por parte de los seres humanos? Desecar las marismas, abrir canales, destruir los bosques viejos por el fuego o el hierro; en su lugar crear pastizales y campos arables para que el buey abra sus surcos, de modo que una nueva naturaleza salga de sus manos $^{30}$. Acciones humanas encaminadas a la modificación de la naturaleza y la creación de paisajes.

El ministro de Relaciones Interiores y Exteriores, Juan José Espinoza de los Monteros, se declaró partidario de uno de esos nuevos paisajes: la agricultura. En su opinión, era una actividad significativa para conseguir el bienestar del pueblo, siempre y cuando, se aprovechara "la verdadera opulencia con que la naturaleza ha enriquecido a la nación mexicana" ${ }^{31}$. José María Gaxiola, gobernador del Estado Interno de Occidente, depositó en

27 Armando Quijada Hernández, "Sonora. Génesis de su soberanía”, en Historia General de Sonora III. Período del México independiente 1831-1883, (Coordinador) Juan Antonio Ruibal Corella (Hermosillo: Gobierno del Estado de Sonora), 1985.

28 Ignacio Zúñiga, Rápida, 93.

29 Georges Louis. Leclerc, Obras completas (España: Versión digitalizada de la Universidad Complutense de Madrid), 95-96.

$6230 \quad$ Georges Louis, Leclerec, Obras, 96.

31 Memoria del Ministerio de Relaciones Interiores y Exteriores de la República Mexicana leída en la Cámara de Diputados el 10 y en la de Senadores el 12 de enero de 1827 (México: Imprenta de Mariano Ontiveros, 1827), 20-21. 
la redacción de una ley agraria "la prosperidad a que los tenía destinados la naturaleza" 32 . Por su parte, Ignacio Zúñiga, fue un convencido de que la explotación de las tierras incultas de los valles del Mayo y Yaqui, significaba sacar provecho de "las grandes ventajas con que invita la naturaleza"33. En 1854, Manuel Monteverde, al igual que los ya mencionados, deseaba la transformación de los inmensos terrenos estériles de Sonora en campos en donde debían brotar "mil veneros de riqueza y felicidad"34.

La voz de élite sonorense conformada por propietarios de tierras, comerciantes, propietarios de molinos harineros y dueños de minas, se había expresado: la naturaleza al servicio de los hombres. Por lo tanto, la propuesta de Ignacio Zúñiga, de que tanto empresarios nacionales como extranjeros "sangrasen los ríos y establecieran plantaciones" $"$, tendría que cumplirse o como dijo, Antonio Goycoolea, darle "vida a los terrenos que han estado muertos y nulos para la agricultura" 36 .

\section{La construcción del paisaje agrícola en el Valle del Mayo, 1863-1904}

Como ya lo observamos, la práctica de la agricultura por parte de los mayos se realizaba en las tierras cercanas a las márgenes del río Mayo, cuyas avenidas las irrigaban. Este método de cultivo, era de poco impacto respecto a la afectación de la vegetación de la llanura semidesértica. Sin embargo, era expresión de un paisaje construido por los mayos. Al margen de dicha práctica, en la parte media y baja de la cuenca del río Mayo, tuvo lugar la ocupación del espacio por medio de composiciones y denuncios de las tierras realengas a partir de los años 60 del siglo XVIII.

Los nuevos propietarios de tierras dedicadas al pastoreo de diferentes tipos de ganado, se asentaron al lado de misioneros y pueblos indios, ge-

32 Exposición sobre el estado actual de la Administración Pública del Estado Interno de Occidente leída por el gobernador José María Gaxiola ante la Asamblea Legislativa del mismo Estado el 2 de marzo de 1829, 1829, 6.

33 Ignacio Zúñiga, Rápida, 40.

34 Archivo General Agrario-Grupo Documental Histórico de Terrenos Nacionales, Sonora, Asunto: Diversos 1. 29 (22) 247.

35 Ignacio Zúñiga, Rápida, 55.

36 Archivo Histórico del Agua (AHA) Fondo: Aprovechamientos Superficiales, caja 1287/exp., 17608/ ff. $24-24 \mathrm{v}$. 
nerándose una tensión entre los primeros y los últimos, no en torno a la propiedad, sino sobre el respeto de los "límites" de las mismas ${ }^{37}$. Los indios de los pueblos mayos enarbolaron como una de sus demandas, ya en los tiempos de la vida independiente de México, la medida de los fundos legales de sus pueblos y la entrega de un sitio de ganado mayor para el pastoreo de sus animales.

La primera embestida en forma contra la naturaleza de la llanura semidesértica la llevaron a cabo los hermanos Martín, José de Jesús y Francisco Salido, socios de la Compañía Salido Hermanos. En el año de 1863, como parte de su plan de negocios acorde con la visión de futuro de los integrantes del Ayuntamiento de Álamos de 1830 -en las tierras fértiles de los valles del Yaqui y Mayo, se podrían alcanzar grandes producciones que algún día llamarían la atención del mundo-, acordaron invertir parte de su capital en la apertura de un canal de derivación de las aguas en la margen derecha del río Mayo. Con dicha obra hidráulica iban a irrigar las tierras de su hacienda Tres Hermanos, ubicada en la parte media de la cuenca del citado río, al noreste del pueblo de Navojoa.

Estos actores sociales con la acción que emprendieron dieron inicio a la expansión de la frontera agrícola en el valle meridional del estado de Sonora. La dilatación del canal fue de un poco más de diez kilómetros desde la bocatoma de agua ubicada a tres kilómetros aguas arriba del cerro llamado Mezcales hasta las labores de riego de la hacienda Tres Hermanos, distante del pueblo mestizo de Navojoa a 25 kilómetros y a una altitud de $80 \mathrm{msnm}$. Los trabajos de desmonte de la vegetación originaria por parte de algunos mayos y mestizos, alcanzó las 200 hectáreas. En la extensión ya despejada, los hermanos Salido, cultivaron trigo, maíz y frijol ${ }^{38}$. Sin embargo, siguieron dependiendo del volumen de las lluvias de verano e invierno, para mantener en producción el nuevo paisaje agrícola. El trinomio tierra, agua y obras hidráulicas, marcaba el inicio de la agricultura intensiva en el valle del Mayo. la tierra desmontada obtuvieron del gobierno estatal 318 litros por segundo. La obra hidráulica entró en operación en febrero de 1865. 
El monto invertido en la mencionada obra hidráulica pasó a un segundo plano para los hermanos Salido. Estos, como empresarios innovadores estaban convencidos de la importancia de la misma, ya que en su opinión contribuian a la prosperidad de los habitantes de la entidad sonorense gracias a la producción agrícola. Asimismo, vieron en su acción como "el medio más eficaz para engendrar el amor al trabajo y por consiguiente el estímulo a la paz entre los mayos que tantos y repetidos males causan al Estado con sus continuas revueltas" 39 .

Los hermanos Salido, convocaban a los mayos a integrarse como trabajadores y superar por este camino las diferencias entre los distintos actores sociales asentados en la ya mencionada cuenca. A la agricultura intensiva le otorgaron una misión civilizadora; redimir a los mayos asentados en los pueblos cercanos a su hacienda. Por su parte, el gobernador del estado, Ignacio Pesqueira, -partidario del progreso entendido como una marcha continua hacia algo siempre mejor-, observó en la obra hidráulica de los hermanos Salido, un avance de la sociedad sonorense.

Su entusiasmo lo llevó a violentar lo establecido en el Reglamento económico para la distribución y conservación de las aguas en los pueblos de Sonora de 1843, que facultó a los ayuntamientos sonorenses a otorgar concesiones de aguas a los particulares. Al margen de lo establecido en la norma, Pesqueira le encomendó tal tarea al prefecto del distrito de Álamos, Carlos E. Gaxiola ${ }^{40}$. Lo anterior nos muestra la tensión entre los representantes de los dos niveles de gobierno, por el control político del recurso agua. El Ayuntamiento de Álamos, no había perdido sus facultades en la materia. La injerencia del gobierno estatal estaba fuera de lugar. Gaxiola actuó, en consecuencia, con la comisión conferida y les concedió a los citados hermanos Salido dos bueyes de agua por segundo con todos los privilegios por haber sido "los primeros en utilizar las aguas del río Mayo con una obra tan costosa y benéfica bajo todos los aspectos" ${ }^{41}$. Lo aseverado por Gaxiola, es la expresión del discurso de todo funcionario de

39 AHA, Fondo: Aprovechamientos Superficiales, caja 4599 /expediente 61235/ f. 3.

40 AHA, Fondo: Aprovechamientos Superficiales, caja 4599/ expediente 61235 /f. 3v.

41 AHA, Fondo: Aprovechamientos Superficiales, caja 4599/ expediente 61235/ ff. 4-4v. Seguían haciendo uso de una medida antigua en materia de aguas. Un buey de agua equivale a 119 litros. 
gobierno, partidario del progreso y un reconocimiento a la acción realizada por los hermanos Salido.

Sin reparar en lo más mínimo en la afectación del ambiente -caracterizado por la abundancia de vegetación arbustiva-, y que se observaba por los propietarios de tierras como un obstáculo para el avance de la frontera agrícola, lo reiteramos, dio inicio el desmonte y la agricultura bajo riego. La ruta trazada por los hermanos Salido, la siguieron otros propietarios de tierras asentados en el valle del Mayo.

Uno de esos propietarios fue Antonio Goycoolea, originario y vecino de Álamos, dueño de la hacienda Santa Bárbara, ubicada en la margen izquierda del río Mayo, enfrente de la hacienda Tres Hermanos. Su proyecto hidráulico contemplaba la apertura de un canal principal y tres canales secundarios.

Con dichas obras hidráulicas se iba a mover un molino de trigo, regar las tierras de labor de la hacienda y de la huerta. El canal principal tuvo un desarrollo aproximado de 12 kilómetros, desde la bocatoma hasta su comparto, serpenteando entre el río Mayo y el cerro de Guadalupe. En el comparto, tres canales secundarios conducirían el agua; uno para regar las tierras altas de la labor de 5 a 6 kilómetros; otro, de 500 metros con término en un almacenamiento para su uso en el riego de las tierras del bajío de la labor; y otro, de un kilómetro a pasar por el terreno de la casa de la hacienda hasta donde está la caída de ocho metros serpenteando entre el río Mayo y el cerro de Guadalupe ${ }^{42}$.

Goycoolea, al terminar las obras hidráulicas antes descritas, abrió al cultivo, claro está después del desmonte realizado por los trabajadores, 200 hectáreas. En dicha prolongación se cultivaron las mismas semillas que en la hacienda Tres Hermanos y en corta escala, alfalfa ${ }^{43}$. Goycoolea, como vecino de los hermanos Salido, conoció el camino utilizado por estos para obtener la concesión de aguas. Por lo tanto, le pidió al prefecto del distrito

42 AHA, Fondo: Aprovechamientos Superficiales, caja 1930/ exp. 29032. La mayor parte del canal se excavó en roca y el resto en conglomerado de tierra y boleo.

43 AHA, Fondo: Aprovechamientos Superficiales, caja 1930/ exp. 29032. 
de Álamos, el uso de sus buenos oficios ante el gobernador Pesqueira, para la entrega del permiso correspondiente, con el ánimo de "darle vida a los terrenos que han estado muertos y nulos para la agricultura durante una larga y no interrumpida serie de años sin dar a sus primeros propietarios las ventajas de que son capaces por su naturaleza y buena calidad"44.

La percepción de los propietarios de tierras respecto a la naturaleza es que estaba allí a su disposición. Al igual que los hermanos Salido, Goycoolea fue un convencido de la importancia de su obra porque de manera inmediata daría trabajo a buen número de individuos. Así, estos junto con sus familias se convertirían:

“...en el muro de contención contra las incursiones de yaquis y mayos dedicados al saqueo y se podría rescatar a un número considerable de individuos de la clase proletaria tan digna de patrocinio y consideración que por falta de trabajo se ven con frecuencia arrastrados al ejercicio de perniciosas costumbres y de vicios que los convierten en desgracia en una carga pesada para la sociedad" 45 .

Goycoolea, por medio de su dicho puso ya en escena a otros actores sociales: los trabajadores de diferente origen étnico, procedentes de diferentes lugares de Sonora y de otros estados de la República mexicana, con una tarea por cumplir. Mientras a los mayos los colocó en una condición degradante. Goycoolea no dejó al margen su interés personal. El capital a invertir en la apertura del canal de derivación, lo iba a recuperar con los ingresos de la venta de la producción agrícola en el mercado nacional e internacional.

Goycoolea, ante el reconocimiento por parte del gobernador Pesqueira, de la falta cometida al intervenir en el tema de la concesión de aguas de los ríos, asunto de la competencia de los ayuntamientos sonorenses, señalada en el Reglamento ya mencionado y ratificada en la fracción I del artículo 60 de la Ley de Administración Interior del Estado de Sonora de 14 de

45 AHA, Fondo: Aprovechamientos Superficiales, caja 1287 /expediente 17608/ ff. 23. 
mayo de $1863^{46}$, presentó el 21 de agosto del mencionado año, su solicitud de concesión de aguas ante el presidente del Ayuntamiento de Álamos, Quirino Corbalá ${ }^{47}$.

En la sesión del 1 de septiembre, el Cabildo dio por admitida la petición y acordó que el regidor Luis López llevara a cabo una visita in situ al lugar donde Goycoolea pretendía abrir su canal. La medida fue con el fin de comprobar si la obra hidráulica a construir, afectaba o no a la propiedad o intereses de otros actores sociales ${ }^{48}$. De la información obtenida por el regidor López dependía la decisión de la Corporación en este asunto.

El regidor López, en cumplimiento de la encomienda asignada, se trasladó al pueblo de Conicari, con población mayo y mestiza. En este lugar citó a Miguel Ruiz, propietario del rancho Los Mezcales, debido a que el canal pasaría por su propiedad. El ranchero Ruiz, dijo que había autorizado el paso de la obra - derecho de servidumbre-, por la simple razón que él también se beneficiaría con el agua en el riego de su tierra. Cubierto este primer asunto, el integrante del Cabildo alamense convocó a Juan Bórquez, Rafael Gómez, Francisco Zazueta y Gregorio Urbalejo, codueños del puesto llamado Cercos de los Güicos, por ser colindantes de la hacienda Santa Bárbara. Todos ellos avalaron con el mismo argumento de Ruiz el proyecto hidráulico de Goycoolea.

Con sustento en la información vertida por los individuos líneas arriba mencionados, Luis López concluyó que el interés particular no sería afectado con la obra hidráulica. Al contrario se vería favorecido. El siguiente punto a desahogar fue comprobar que la obra proyectada no sería en perjuicio del interés público. En este tema, le tocó al propio López dar la respuesta en los siguientes términos: "Obras del tipo que estaba realizando Goycoolea daban trabajo a los pobres, y ponían en movimiento la producción agrícola, actividad que era una de las fuentes de la riqueza pública la cual, por desgracia había faltado hasta la época presente" ${ }^{\text {"49 }}$. 
En las palabras de López, además del lamento está presente la idea de la construcción del paisaje agrícola. El edil de Álamos con sustento en el dictamen de López, fue de la opinión que se debía otorgar la concesión de aguas al solicitante en cantidad suficiente aún en las estaciones secas ${ }^{50}$. La última palabra en este asunto la tenía el Cabildo. En la sesión del 1 de febrero de 1873, acordaron otorgarle a Goycoolea la concesión por dos bueyes de agua del río Mayo, para ser usadas en el riego de las tierras de la hacienda Santa Bárbara ${ }^{51}$. El título de la concesión se expidió el 11 de febrero ${ }^{52}$.

Otros que participaron en la construcción de paisajes agrícolas fueron Jesús Morales, Ignacio Castro y Jesús Ramírez, en representación de los vecinos del pueblo de Tesía. Este se ubica al norte de Navojoa a una distancia de 12 kilómetros y a una altitud de $50 \mathrm{msnm}$. El nombre que le pusieron al canal fue Los Pobres de Tesía, para destacar de alguna manera su diferencia social con los hermanos Salido y Goycoolea. Con el funcionamiento de la obra hidráulica se iba a irrigar las tierras del citado pueblo, situadas entre las haciendas del Molino, Mochibampo y Bayehue, pertenecientes a Felipe Martínez, Bernardo García y Campoy Hermanos respectivamente. La extensión del canal también alcanzó los 12 kilómetros ${ }^{53}$.

Por lo tanto, Morales, Castro y Ramírez, a nombre de los vecinos del citado pueblo solicitaron al Ayuntamiento de Navojoa la concesión de tres bueyes de agua. La Corporación mencionada en uso de sus facultades otorgadas por la ya mencionada Ley de Administración Interior del Estado de Sonora de 14 de mayo de 1863, en sesión del día 20 de enero de 1879 aprobó la concesión por 477 litros de agua para uso agrícola ${ }^{54}$. La apertura de canales en la cuenca del río Mayo, era una decisión de los actores sociales vinculados con el recurso tierra.

50 AHA, Fondo: Aprovechamientos Superficiales, caja 1287/ expediente 17609/ f. 19-19v.

51 AHA, Fondo: Aprovechamientos Superficiales, caja 1287/ expediente 17609/ f. 20.

52 AHA, Fondo: Aprovechamientos Superficiales, caja 1287/ expediente 17609/ f. 21.

53 AHA, Fondo: Aprovechamientos Superficiales, caja 4597/ expediente 61192/ f. 13.

54 AHA, Fondo: Aprovechamientos Superficiales, caja 4597/ expediente 61192/ f. 13. 
En este avance de la frontera agrícola en las tierras de propiedad individual o perteneciente a los pueblos, también intervino Ángel Almada. Este, era propietario de la hacienda San Pedro, ubicada entre los pueblos de Etchojoa y San Pedro. Ambos pueblos se encuentran en la parte baja de la cuenca del río Mayo. Almada, al igual, que los hermanos Salido y Goycoolea, no minimizó la importancia de la apertura de un canal de derivación de las aguas del río Mayo, por parte de su Compañía, ya que otorgaría "trabajo a un gran número de personas" 55 . Los propietarios de tierras, como parte de uno de los grupos de actores sociales, en términos discursivos, destacaron el papel de mano de obra de los habitantes de los pueblos. Nunca pensaron otorgarles beneficios de otra índole.

Almada, actuando en el marco de la legislación emitida por la Cámara de Diputados federal:

Ley de 5 de junio de 1888, sobre vías generales de comunicación y la Ley de 6 de junio de 1894, sobre aprovechamientos de aguas federales, presentó su solicitud de aguas ante Leandro Fernández, secretario de Fomento, Colonización, Industria y Comercio. El citado funcionario autorizó mediante la firma el 3 de abril de 1902 del Contrato respectivo la concesión de diez mil litros de agua por segundo ${ }^{56}$. Almada, con el permiso en sus manos, junto con Alberto Ramos, Óscar Ocharán, Lauro y Ángel Quirós, Manuel Larraguibel e Ignacio Vidaurreta, formaron la Compañía Agrícola del río Mayo el 22 de julio de 1902, con un capital de cien mil pesos. Su propósito era la producción agrícola y los negocios inherentes a dicha actividad económica ${ }^{57}$.

Aldama, después del trámite correspondiente ante la autoridad del ramo le transfirió la concesión de aguas a la Compañía Agrícola del Río Mayo. Esta, dio inicio a los trabajos de apertura del canal en el punto llamado Tierra Colorada, localizado a unos kilómetros al suroeste del pueblo San Ignacio, Cohuirimpo. La cuadrilla de trabajadores fue dirigida por Manuel

55 Diario Oficial, 11 de abril de 1902, t. LIX, número 36, 7-9. 49.

56 Diario Oficial, 11 de abril de 1902, t. LIX, número 36, 7-9. 49. Con ambas leyes, el gobierno federal asumió el control de las aguas de los ríos, quitándoles a los ayuntamientos para el caso de Sonora, dicha facultad.

57 AHA, Fondo: Aprovechamientos Superficiales, caja 4589/ exp., 61094/ ff. 89-101. 
Y. Valenzuela. La obra hidráulica se terminó en julio de 1903, con una extensión de quince kilómetros desde la bocatoma ubicada en el sitio llamado Tierra Colorada hasta las labores de la hacienda San Pedro ${ }^{58}$. Cabe decir que la fuente no registra la cantidad de hectáreas bajo riego, pero, por el volumen de agua concesionado nos atrevemos a decir que se dio el desmonte de más de 2500 hectáreas, pertenecientes a los socios de la mencionada Compañía. La construcción de paisajes agrícolas seguía avanzando.

En sintonía con la idea de explotar el potencial de la llanura semidesértica, los miembros de la familia Salido Moreno, la Sociedad José María Salido y Compañía, al igual que su padre y tíos, tuvieron como prioridad dotar de riego a las tierras de la hacienda Rosales, que durante años habían estado improductivas ${ }^{59}$. Para ellos, al igual que en los casos anteriores, era indispensable la apertura de un canal de derivación de las aguas del río Mayo. Tal obra tuvo una dilatación de 12 kilómetros. El sitio llamado Peñitas fue elegido para la construcción de la bocatoma, aguas arriba del pueblo de Tesía en la margen izquierda del río Mayo. Tanto el canal, como la compuerta y el vertedor de demasías se terminaron el 27 de marzo de $1904^{60}$. Ya con la obra hidráulica concluida las cuadrillas de trabajadores entraron en acción para desmontar 600 hectáreas a utilizar en la siembra de garbanzo y la construcción de otro paisaje agrícola, cuya producción competía en el mercado internacional.

\section{A MANERA DE CONCLUSIÓN}

A través de las percepciones expresadas por los diferentes actores sociales en torno a los componentes del ambiente tanto de la llanura semidesértica como de otras regiones fisiográficas de Sonora, nos dan la pauta para decir que emergió una construcción social sobre el potencial de las tierras que eran bañadas por los desbordamientos de ríos y arroyos, dando paso, en un primer momento, a la práctica de la agricultura por parte de los pueblos indios asentados a lo largo del curso de aquellos. En este sentido, también, mayos, yaquis, seris, ópatas, construyeron paisajes agrícolas en dichas tierras.

58 AHA, Fondo: Aprovechamientos Superficiales, caja 4589/ expediente 61094/ f. 2.

59 AHA, Fondo: Aprovechamientos Superficiales, caja 4599/ exp. 61235/ f. 1. La citada hacienda se ubicaba a unos cuantos kilómetros al norte del pueblo de Navojoa.

60 AHA, Fondo: Aprovechamientos Superficiales, caja 4599/ expediente 61235/ ff. 82-85. 
Los propietarios de tierras con el conocimiento de esa experiencia de vida y cultura, se abocaron a la apertura de canales de derivación de las aguas del río Mayo, con el propósito de avanzar la frontera agrícola más allá de las márgenes de la corriente superficial, cristalizando el anhelo expresado tanto por ellos como por otros individuos residentes en Sonora o de paso, de establecer una agricultura bajo riego, que no es otra cosa, que un paisaje.

\section{Bibliografía}

\section{Archivos}

Archivo General de la Nación AGN.

Archivo General del Estado de Sonora AGES.

Archivo Histórico del Agua AHA.

Diario Oficial DO.

Archivo Franciscano - Biblioteca Nacional de México AF-BNM.

\section{Fuentes secundarias}

Bojórquez Jusaino, María del Carmen. "Del Pitico a distrito de Hermosillo. La colonización del espacio, 1744-1852. Una descripción a través de la privatización de la tierra" (Tesis de Licenciatura, Universidad de Sonora, 2004).

Escobar Ohmstede Antonio. "Cambios en el paisaje hidroagrario ¿La Revolución un detonante? El caso de San Luis Potosí (1910-1940)”. Relaciones. Estudios de historia y sociedad Vol. XXXIV, No. 136, (2013).

Escudero, José Agustín de. Noticias Estadísticas de Sonora y Sinaloa. Hermosillo: Universidad de Sonora, 1997.

Exposición sobre el estado actual de la Administración Pública del Estado Interno de Occidente leída por el gobernador José María Gaxiola ante la Asamblea Legislativa del mismo Estado el 2 de marzo de 1829. Guadalajara: Imprenta del Supremo Gobierno, 1829.

Jiménez Sierra, Cecilia Leonor. "Las cactáceas mexicanas y los riesgos que enfrentan”. Revista Digital Universitaria, Vol. 12, No. 1, (2011).

Lafora, Nicolás de. Relación del viaje que hizo a los presidios internos situados en la frontera de la América Septentrional, perteneciente al Rey de España. México: Editorial Pedro Robredo. 1939.

Leclerc, Georges Louis. Obras completas. España: Versión digitalizada de la Universidad Complutense de Madrid. 
Lorenzana Durán, Gustavo. “Tierra, agua y mercado en el distrito de Álamos, Sonora, 1754-1915”. (Tesis de Doctorado en, Instituto de Investigaciones Histórico-Sociales de la Universidad Veracruzana, 2002). Memoria del Ministerio de Relaciones Interiores y Exteriores de la República Mexicana leída en la Cámara de Diputados el 10 y en la de Senadores el 12 de enero de 1827. México: Imprenta del Supremo Gobierno, 1827.

Nentuig, Juan. El Rudo ensayo. Descripción geográfica, natural y curiosa de la provincia de Sonora, 1764. México: INAH, 1977.

Pérez de Ribas, Andrés. Historia de los Triumphos de nuestra Santa Fe. México: Siglo XXI Editores-DIFOCUR, 1992.

Quijada Hernández, Armando. Sonora. Génesis de su soberanía. Hermosillo: Gobierno del Estado de Sonora, 1981.

Quijada Hernández, Armando. "Sonora. Génesis de su soberanía”. En Historia General de Sonora III. Periodo del México independiente 1831-1883, (Coordinador) Juan Ruibal Corella. Hermosillo: Gobierno del Estado de Sonora, 1985.

Radding, Cynthia. Paisajes de poder e identidad: fronteras imperiales en el desierto de Sonora y bosque de la Amazonia. México: CIESAS-UAM-Azcapotzalco-El Colegio de Sonora, 2005.

Tamarón y Romeral, Pedro. Demostración del vastísimo obispado de la Nueva Vizcaya, 1765. Durango, Sinaloa, Sonora, Arizona, Nuevo México, Chihuahua y porciones de Texas, Coahuila y Zacatecas. México: Antigua Librería Robredo, 1937.

Velázquez Aguirre, Luis y Anselmo Ordaz Ayala. "Provincias hidrogeológicas de México”. En Boletinsgm.igeolcuunam.mx/bsgm/vols/ época 03/5201/velazquez- aguirre.pdf http://www.ceasonora.gob. $\mathrm{mx} / \operatorname{archivos} / \mathrm{admin} / .(20$ de abril de 2013)

www.sonora.sitecproduce.org.mx/Estado/fisiografía\#fisiografía. Consultada realizada (20 de abril de 2013)

Zúñiga, Ignacio. Rápida ojeada al Estado de Sonora (1835). Hermosillo: Gobierno del Estado de Sonora, 1985.

Para citar este artículo: Lorenzana Durán, Gustavo. “Canales de riego: creación de un paisaje agrícola en el valle del Mayo, Sonora, 1863-1904”, Historia Caribe Vol. X No. 26 (Enero-Junio 2015): 53-73.

DOI: http://dx.doi.org/10.15648/hc.26.2015.3 